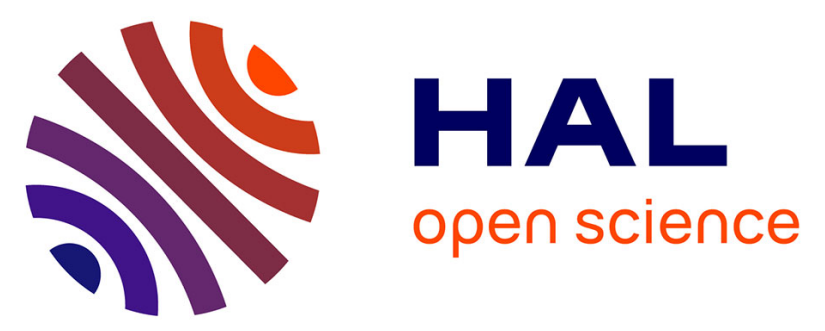

\title{
Quantifying tumor vascular heterogeneity with DCE-MRI in complex adnexal masses: A preliminary study
}

Isabelle Thomassin-Naggara, Narimane Soualhi, Daniel Balvay, Emile Darai, Charles-Andre Cuenod

\section{To cite this version:}

Isabelle Thomassin-Naggara, Narimane Soualhi, Daniel Balvay, Emile Darai, Charles-Andre Cuenod. Quantifying tumor vascular heterogeneity with DCE-MRI in complex adnexal masses: A preliminary study. Journal of Magnetic Resonance Imaging, 2017, 46 (6), pp.1776-1785. 10.1002/jmri.25707. hal-01668850

\section{HAL Id: hal-01668850 \\ https://hal.sorbonne-universite.fr/hal-01668850}

Submitted on 20 Dec 2017

HAL is a multi-disciplinary open access archive for the deposit and dissemination of scientific research documents, whether they are published or not. The documents may come from teaching and research institutions in France or abroad, or from public or private research centers.
L'archive ouverte pluridisciplinaire HAL, est destinée au dépôt et à la diffusion de documents scientifiques de niveau recherche, publiés ou non, émanant des établissements d'enseignement et de recherche français ou étrangers, des laboratoires publics ou privés. 
Quantitative dynamic contrast-enhanced MR imaging analysis of complex adnexal masses: A preliminary study

Isabelle Thomassin-Naggara, Narimane Soualhi, Daniel Balvay, Emile Darai,

\section{Charles-André Cuenod}

Key points

Quantitative DCE MR imaging allows accurate differentiation between malignant and benign tumours

Quantitative DCE MR imaging may help to predict peritoneal carcinomatosis associated with ovarian tumors

Quantitative DCE MR imaging allows to distinguish primary invasive ovarian tumours from borderline tumours 


\section{ABSTRACT}

Objective: To evaluate the ability of quantitative dynamic contrast-enhanced magnetic resonance imaging (DCE-MRI) to differentiate malignant from benign adnexal tumours.

Methods: Fifty-six women with 38 malignant and 18 benign tumours who underwent MR imaging before surgery for complex adnexal masses were included. Microvascular parameters were extracted from DCE-MRI series, using a pharmacokinetic model in the solid tissue of adnexal tumours. These parameters were tissue blood flow $\left(\mathrm{F}_{\mathrm{T}}\right)$, blood volume fraction $(\mathrm{Vb})$, permeability-surface area product (PS), interstitial volume fraction (Ve), lag time (Dt) and area under the enhancing curve (rAUC). Area under the Receiver Operating Curve (AUROC) was calculated as a descriptive tool to assess the overall discrimination of parameters.

Results: Malignant tumours displayed higher $\mathrm{F}_{\mathrm{T}}, \mathrm{Vb}$, rAUC and lower Ve than benign tumours $(p<0.05)$. $\mathrm{F}_{\mathrm{T}}$ was the most relevant factor for discriminating malignant from benign tumours (AUROC=0.86). Primary invasive ovarian tumours displayed higher $\mathrm{F}_{\mathrm{T}}$ and shorter Dt than borderline tumours. Malignant tumours with associated peritoneal carcinomatosis displayed a shorter Dt than those without peritoneal carcinomatosis at surgery $(p=0.01)$.

Conclusion: Quantitative DCE-MRI is a feasible and accurate technique to differentiate malignant from benign adnexal tumours and could potentially help the oncological surgeon to choose the better treatment planning for patients.

Key words: Perfusion, MRI, Complex adnexal masses, Dynamic contrast-enhanced MRI, Ovarian tumour 


\section{INTRODUCTION}

During the past decade, dynamic contrast-enhanced MR imaging (DCE-MRI) has proved to be useful for characterising pelvic solid tissue [1, 2]. The contribution of DCE-MRI to ovarian tumours has been demonstrated by many authors $[3,4]$ and especially for the characterisation of complex or indeterminate adnexal masses (ovarian and tubal masses) at ultrasound [5]. In this setting, descriptive analysis allows three types of curve to be described which are useful for differentiating benign from malignant tumours [6]. Using semi-quantitative analysis, the maximal slope of the time-intensity curve has been shown to be correlated with microvessel parietal immaturity of ovarian malignant tumours and is therefore an accurate means of differentiating benign from malignant epithelial tumours [5]. However, descriptive and semi-quantitative analyses are based on image signal intensity analysis and lack reproducibility because they do not take into account the individual variability of the arterial input function.

In this setting, advances in fast imaging techniques enable pharmacokinetic physiological modelling using quantitative DCE-MRI analysis [1, 7-9]. However, there are currently no available data on the use of this technique to analyse the dynamic enhancement behaviour of benign and malignant adnexal tumours.

We therefore sought to determine the feasibility of MR pharmacokinetics modelling in adnexal tumours and to evaluate the ability of perfusion kinetic parameters to differentiate benign from malignant tumours using quantitative DCE-MRI. 


\section{MATERIALS AND METHODS}

Our institutional ethics committee approved the study and granted a waiver of informed consent.

Between May 2006 and February 2008, our MR imaging database was retrospectively queried to identify women who underwent MR imaging with dynamic contrast-enhanced imaging for ultrasound-complex adnexal masses with subsequent surgery with pathological correlation $(n=87)$.

Among these 87 patients, DCE-MRI quantitative analysis was not possible in 31 patients (reasons for exclusion: no solid component [ $n=14]$, sagittal acquisition plane [ $n=9]$, technical problem including injection or artefact $[n=4]$ and data conversion $[n=4])$. Thus, our final cohort included 56 patients (mean age, 54.5 years; age range, 25-87 years).

At surgery, among these 56 patients, ovarian cystectomy was performed in one woman, salpingo-oophorectomy in 20 women (unilateral in 6 and bilateral in 14), bilateral salpingo-oophorectomy with hysterectomy in 28 women, and omentectomy and peritoneal biopsies in 7 women. When bilateral lesions had the same histology $(n=18)$, only the most complex mass was included in the statistical analysis to limit the intra-correlation effect.

Histopathological findings included 18 benign lesions (9 epithelial cystadenomas, 8 sex-cord tumours, and 1 hydrosalpinx) and 38 malignant tumours (5 epithelial borderline cystadenomas, 27 cystadenocarcinomas, 1 sex-cord stromal tumour [granulosa cell tumour], 3 metastases and 2 tubal cancers). Peritoneal carcinomatosis was detected at surgery in 25 of the 38 malignant tumours (65.7\%) (22 ovarian cystadenocarcinomas, 2 metastases and 1 tubal cancer). 


\section{MR imaging technique}

Magnetic resonance imaging sequences were acquired at $1.5 \mathrm{~T}$ (Sonata, Siemens, Erlangen, Germany) using a phased array pelvic coil. All sequences were acquired with saturation bands placed anteriorly and posteriorly to eliminate the high signal from subcutaneous fat. Patients fasted for $3 \mathrm{~h}$ and received an antispasmodic drug intravenously (10 mg of tiemonium methylsulphate; Visceralgine; Organon, Livron, France) immediately before MR imaging to reduce bowel peristalsis.

Before injection, the following sequences were acquired: sagittal (TSE) T2-weighted turbo spin-echo $(\mathrm{TR}=5050, \mathrm{TE}=121$, slice thickness $=5 \mathrm{~mm}$, gap interslice $=1 \mathrm{~mm}, \mathrm{FOV}$ $=280 \times 225$, matrix $=512 \times 245, \operatorname{NEX}=2$, number of slices $=25$, acquisition time $=178$ sec) and axial T2-weighted turbo spin-echo $(\mathrm{TR}=6790, \mathrm{TE}=89$, slice thickness $=5 \mathrm{~mm}$, gap interslice $=1 \mathrm{~mm}, \mathrm{FOV}=370 \times 275$, matrix $=512 \times 187, \mathrm{NEX}=2$, number of slices $=$ 45, acquisition time $=185 \mathrm{sec}$ ) and axial gradient-echo T1-weighted sequences with and without fat suppression $\left(\mathrm{TR}=170, \mathrm{TE}=4.76\right.$, flip angle $=70^{\circ}$, slice thickness $=5 \mathrm{~mm}$, gap interslice $=1 \mathrm{~mm}, \mathrm{FOV}=320 \times 280$, matrix $=246 \times 145, \mathrm{NEX}=1$, number of slices $=15$, acquisition time $=21 \mathrm{~s})$.

Then, an axial or axial oblique dynamic contrast-enhanced (DCE) T1-weighted gradient-echo sequence (2D FLASH) $\left(\mathrm{TR}=27, \mathrm{TE}=2.24\right.$, flip angle $=80^{\circ}$, slice thickness $=5 \mathrm{~mm}$, gap interslice $=1 \mathrm{~mm}, \mathrm{FOV}=400 \times 200$, matrix $=256 \times 128, \mathrm{NEX}=1$, number of slices $=3$ ) was acquired during a total acquisition time of $320 \mathrm{sec}$ through the tumour at the level where "solid tissue" was observed on non-enhanced MR images, as previously described [6]. "Solid tissue or solid component", as defined by Timmerman et al. [10], comprises vegetations, solid portions, and thickened septa. Gadolinium chelate (DOTAREM®, Guerbet, Aulnay, France) was given at a dose of $0.2 \mathrm{~mL} \cdot \mathrm{kg}^{-1}$ via a Power Injector (Medrad, Maastricht, The Netherlands) at a rate of $2 \mathrm{~mL} \cdot \mathrm{s}^{-1}$, followed by $20 \mathrm{~mL}$ of 
normal saline to flush the tubing. Images were obtained at 2.4-s intervals beginning $10 \mathrm{~s}$ before the bolus injection, for a total of $320 \mathrm{~s}$ and a total of 130 time frames.

Finally, delayed enhanced axial and sagittal T1-weighted gradient-echo images with breath-hold were performed 6 min after gadolinium injection.

\section{MR imaging analysis}

Morphological criteria

Tumour size, presence of a solid and/or cystic component, presence of thickened septa, vegetation and/or a solid portion within a cystic tumour were recorded. The cystic component was defined as tissue that had long $\mathrm{T} 1$ and $\mathrm{T} 2$ characteristics and showed no enhancement after injection. A tumour was defined either as purely solid or as mixed (tumour with solid and cystic components). By definition, the solid component showed enhancement after injection. The size of the solid tissue was also recorded.

Finally, the presence of associated peritoneal carcinomatosis on MR imaging was noted.

\section{Regions of interest}

Dynamic data were analysed using dedicated software developed in-house with MatLab 7.2 (R2006a; The Mathworks, Natick, MA, USA) and running on a PC (Pentium 4 at $2.8 \mathrm{GHz}$ and $2.5 \mathrm{~GB}$ of RAM memory). All the fittings were based on the LevenbergMarquardt regression method.

One researcher with 5 years' experience in pelvic MR imaging and no knowledge of the patient's clinical information performed the analysis. Two regions of interest (ROIs) were drawn for each examination: within the lumen of an external iliac artery (to record an individual arterial input function) as well as in the solid tissue of the adnexal tumour (Fig. 
1). Signal-time courses of these ROIs were determined over all 130 time frames for pharmacokinetic analysis.

Pharmacokinetic analysis

The external iliac artery signal enhancement curve was used as the arterial input function (AIF) to the pharmacokinetic model (Fig. 2). The signal intensity was converted into concentration equivalents assuming a near linear relationship between contrast agent concentration and signal enhancement within the range of 0-3 mM Gd-DOTA values [9]. These data were validated in our laboratory during a previously published study [11] by phantom experiments using the same MR acquisition parameters:

$S(t)-S(0)=k \cdot C(t)$

where $\mathrm{S}(0)$ and $\mathrm{S}(\mathrm{t})$ are the signal intensities before injection and at time $\mathrm{t}$ after the beginning of the contrast agent injection, respectively, $\mathrm{C}(\mathrm{t})$ is the contrast agent concentration in tissue at time $\mathrm{t}$, and $\mathrm{k}$ depends on the tissue-specific native longitudinal relaxation time, acquisition parameters and the contrast media relaxivity. A haematocrit level of $45 \%$ was considered in large vessels and 33\% in small vessels $[12,13]$.

The molecules of contrast agent can leak through the endothelial wall of capillaries but remain extracellular. Therefore, the evolution of tissue contrast agent concentration follows the equation of a previously published two-compartmental model (M2) with exchanges between the capillary and the interstitial spaces (see Appendix) [11, 14-17]. In addition to tissue blood flow $\mathrm{F}_{\mathrm{T}}\left(\mathrm{mL} \cdot \mathrm{min}^{-1} .100 \mathrm{~mL}^{-1}\right)$ and blood volume fraction $\mathrm{Vb}(\%)$, this model provides the permeability-surface area product PS $\left(\mathrm{mL} \cdot \mathrm{min}^{-1} .100 \mathrm{~mL}^{-1}\right)$, the extracapillary and extracellular (interstitial) volume fraction Ve (\%), and the lag time Dt (s), which is the time required for blood to go to the tissue arterioles from AIF measurement in the large iliac artery. Relative area under the curve (rAUC) was calculated as the ratio 
between the area under the curve of the tumour and the area under the curve of the individual input artery.

Relevance test of the model

The relevance of the proposed model was assessed using quality criteria designed to identify bad fitting and poor contrast-to-noise ratio. Quality criteria were fraction of modelling information (FIM), which identifies poor fit, and fraction of initial information (FII), which calculates the ratio of informative signal compared with total signal [18], a measure of the contrast-to-noise ratio.

\section{Statistical analysis}

Continuous parametric variables were compared using the Mann-Whitney test and categorical variables were compared using Fisher's exact test, as appropriate. Receiver operating curves (ROC) and the area under the ROC curve (AUROC) were calculated as a descriptive tool to assess the overall discrimination of parameters.

A $p$ value of less than 0.05 was considered to indicate a statistically significant difference. Analyses were carried out using MedCalc software (www.medcalc.be, Belgium). 


\section{RESULTS}

\section{Morphological MR characteristics}

Morphological characteristics of adnexal tumours are described in Table 1. In our population, 19 tumours were purely solid and 37 were mixed, including 27 tumours with a solid portion, 16 tumours with vegetations and 13 tumours with thickened septa. No statistical difference regarding type or size of solid tissue was found between benign and malignant adnexal tumours.

Among the malignant tumours $(n=38)$, associated peritoneal carcinomatosis was correctly described on MR imaging in 17/18 tumours (Positive predictive value $=94.4 \%$ ). Among the 20 tumours that did not display any peritoneal nodule on MR imaging, only 12 tumours were not associated with peritoneal carcinomatosis at surgery (Negative predictive value $=60 \%$.

\section{Relevance of the model}

Typical adnexal tumour enhancement curves are shown in Fig. 2. The curve fit allows the capillary and interstitial contribution to tissue enhancement to be separated. Data were fitted both in benign and malignant adnexal tumours with high quality (FMI $=0 \cdot 94[+/-0 \cdot 05]$ and $0 \cdot 96[+/-0 \cdot 03]$, respectively) and displayed a high contrast-to-noise ratio (FII $=0.95[+/-$ $0 \cdot 14]$ and 0.99 [+/-0·001], respectively) (Fig. 2).

\section{Comparison of quantitative DCE-MRI parameters between benign and malignant adnexal tumours}

Malignant adnexal tumours displayed a higher tissue blood flow $\left(\mathrm{F}_{\mathrm{T}}\right)$, a higher blood volume fraction $(\mathrm{Vb})$ and a lower interstitial volume (Ve) than benign adnexal tumours $(p<0.0001, p=0.0006$, and $p=0.04$, respectively) (Table 2). No significant difference 
regarding permeability-surface area product (PS) and lag time (Dt) was found between malignant and benign adnexal tumours; nevertheless, PS tended to be higher for malignant tumours. On the contrary, the rAUC was significantly higher in malignant than in benign tumours $(p=0.0002)$.

The results of ROC analysis of all DCE-MRI parameters are summarised in Table 3. The most relevant factors for discriminating malignant from benign tumours, expressed as the area under the ROC curve, were tissue blood flow $\left(\mathrm{F}_{\mathrm{T}}\right)$ (AUROC=0.86), rAUC (AUROC=0.81) and blood volume fraction (Vb) (AUROC=0.79) (Fig. 3). Using ROC analysis, an $\mathrm{F}_{\mathrm{T}}>39.5$ had a sensitivity of $73.7 \%$ and a specificity of $88.9 \%$ for predicting malignancy.

Comparison of quantitative DCE-MRI parameters between the different subtypes of malignant ovarian tumours

Primary invasive ovarian tumours displayed a higher tissue blood flow $\left(\mathrm{F}_{\mathrm{T}}\right)$ and a lower lag time (Dt) than borderline tumours ( $p=0.001$ and $p=0.02$ ) (Fig. 4). No significant difference regarding blood volume fraction (Vb), permeability-surface area product (PS) and interstitial volume (Ve) was found between primary invasive ovarian tumours and borderline tumours. No difference regarding quantitative MR parameters was found between primary invasive ovarian tumours and metastasis

\section{Comparison of quantitative DCE-MRI parameters between malignant adnexal} tumours with and without peritoneal carcinomatosis

Malignant adnexal tumours associated with peritoneal carcinomatosis detected at surgery displayed a shorter lag time (Dt) (median 3.9 s; interquartile range [2.7-6.2]) than those without peritoneal carcinomatosis at surgery (median 6.5; interquartile range [2.2-9.7]) 
$(p=0.01)$. No difference was found between these two groups of malignant tumours whatever other DCE-MRI parameters were considered.

Using ROC analysis, a Dt $<5.47$ had a sensitivity of $64 \%$ and a specificity of $76.9 \%$ for predicting peritoneal carcinomatosis. Among the eight malignant tumours where peritoneal carcinomatosis was not detected on MR imaging but was depicted at surgery (i.e. false-negatives), $4 / 8$ (50\%) displayed a Dt $<5.47$. Thus, adding Dt to the morphological criteria, peritoneal carcinomatosis could be preoperatively diagnosed in $84 \%$ (21/25) of cases versus $68 \%(17 / 25)$ of cases with morphological criteria alone. 


\section{DISCUSSION}

Our study demonstrates that pharmacokinetic modelling using a comprehensive twocompartmental model is a relevant tool for differentiating malignant from benign adnexal tumours with a high quality and a high contrast-to-noise ratio. Malignant tumours displayed a higher tissue blood flow $\left(\mathrm{F}_{\mathrm{T}}\right)$, a higher blood fraction volume $(\mathrm{Vb})$, a lower interstitial volume (Ve) and a higher relative AUC (rAUC) than benign tumours. Primary invasive ovarian tumors displayed a higher $\mathrm{F}_{\mathrm{T}}$ and a lower Dt than borderline tumours. Moreover, malignant adnexal tumours with associated peritoneal carcinomatosis displayed a shorter lag time (Dt) than those without peritoneal carcinomatosis at surgery.

To our knowledge, our study is the first to evaluate in vivo the microvascular properties of adnexal tumour tissue. By extracting quantitative physiological microcirculation parameters from DCE-MRI data with high time resolution and high signalto-noise ratio, our study shows that a two-compartmental model is comprehensive and accurate for the analysis of the tissue of adnexal tumours.

The most interesting quantitative dynamic MR parameters to distinguish malignant from benign tumours were $\mathrm{F}_{\mathrm{T}}$, rAUC and $\mathrm{Vb}$ with AUROC higher than 0.78. These results are in agreement with physiopathology: malignant tumours are characterised by the presence of additive poorly formed and fragile neoangiogenic vessels [19]. In addition, microvessels of malignant tumours lack a muscular coat and are highly permeable with a low pericyte coverage index and a high VEGFR-2 receptor expression on both epithelial and endothelial cells [20-23]. $\mathrm{F}_{\mathrm{T}}$ and $\mathrm{Vb}$ are higher in malignant adnexal tumours, likely due to the presence of microvessel parietal immaturity. A tissue blood flow $<39.5 \mathrm{ml} \cdot \mathrm{mn}^{-1} .100 \mathrm{ml}^{-1}$ had a high sensitivity (88.9\%) for predicting benignity. Quantitative analysis may therefore help young women wishing to preserve childbearing potential to opt for conservative surgery and may avoid the systematic removal of benign complex adnexal masses in menopausal women. 
Our data confirm that the analysis of early enhancement of adnexal tumours is very useful to characterise solid tissue in complex adnexal tumours $[4,6,24] . \mathrm{F}_{\mathrm{T}}, \mathrm{Vb}$ and $\mathrm{Dt}$ mainly describe the first part of the tissue enhancement curve. Our study confirms that DCE MR imaging is accurate to differentiate borderline from primary invasive ovarian tumours. In accordance with time intensity curve (TIC) and semi-quantitative analysis (i.e. maximal slope and enhancement amplitude) [23], primary invasive ovarian tumours display a steeper and an earlier enhancement with a higher Ft and a lower Dt than borderline tumours. Due to the generally good prognosis associated with these last group of tumours, fertility-sparing surgery has been proposed, underlining the potential crucial role of quantitative DCE MR analysis in the preoperative assessment.

Contrary to TIC or semi-quantitative measurement that led to considerable variation between individual examinations [2], internal reference is not necessary for quantitative analysis (AIF being the individual contrast input reference in quantitative analysis). This notion is important because outer myometrial enhancement, used for enhancement curve analysis for adnexal masses, was demonstrated to be significantly different between postmenopausal women and women of reproductive age with a lower $\mathrm{F}_{\mathrm{T}}$, lower $\mathrm{Vb}$, higher PS, higher Ve and lower Dt [11], and thus the appropriateness of using this organ as an internal reference could be discussed.

Our results also reveal that interstitial volume (Ve) is lower in the tissular component of adnexal malignant tumours than in those of benign tumours. In every tissue, there are three different spaces: blood space (described in our model as Vb), extravascular extracellular or interstitial space (described in our model as Ve) and cellular space (where the gadolinium contrast media do not penetrate). In adnexal tumours, apparent diffusion coefficient (ADC) have been described to be lower or equal in malignant than in benign tumours [25-27]. It is well known that the ADC value assessed by diffusion imaging 
sequence is related to cellular space. Thus, as $(\mathrm{Vb}+\mathrm{Ve})$ described the total volume distribution of contrast agent and because cellular space is not different or higher in malignant than in benign adnexal tumours, if $\mathrm{Vb}$ is higher in malignant than in benign tumours as described in our compartmental model, Ve should be lower in malignant than in benign tumours.

Our results also show that, among malignant tumours, those with peritoneal carcinomatosis at surgery displayed a shorter lag time (Dt) than those without peritoneal carcinomatosis. Tumour neoangiogenesis plays a central role in the growth and spread of tumours and Dt should be provide a means of evaluating the aggressiveness of the tumour, from DCE data with time resolution of a few seconds. Peritoneal carcinomatosis is the main form of dissemination of ovarian cancers and imaging techniques are currently unable to detect accurately all peritoneal implants owing to their potentially very small size whatever the technique used [28, 29]. Complete cytoreductive resection of all macroscopic disease at surgery is one of the main prognostic factors of ovarian carcinoma. Thus, functional criteria that predict peritoneal carcinomatosis are very interesting as new predictors of overall survival to be integrated into clinical prognostic scores.

Recently, Vergote et al. in a European clinical trial group [30] demonstrated that neoadjuvant chemotherapy followed by interval debulking surgery was not inferior to primary debulking surgery followed by chemotherapy as a treatment option for patients with bulky stage IIIC or IV ovarian carcinoma. As in several other applications [31-33], quantitative DCE-MRI analysis gives reproducible parameters [34] that should be very useful in evaluating the tumour response to therapy for these patients.

Finally, DCE-MRI parameters play a potential role in the early prediction of progression in patients with residual ovarian cancer after surgery, thanks to a good correlation with classical serological markers (CA 125, VEGFR-1 and VEGFR-2), and use 
of this technique to predict when subsequent treatment is needed would be of significant benefit [35].

Our study has several limitations: First of all, our population selection could be biased. In this series, no difference was found regarding classical morphological criteria of malignancy because we selected only tumours with solid tissue and thus with a DCE-MRI sequence. This is why no extensive analysis were performed on morphological criteria. However, in our series, the absence of difference regarding the median size of solid tissue between benign and malignant tumours would appear to rule out any major technical DCEMRI analysis bias, because a substantial amount of solid tissue is needed to draw a region of interest on the tissue. Second, interquartile ranges are large for Ve and PS and this likely explains why the accuracy of Ve using AUROC is not so good and that PS tends to be higher in malignant than in benign tumours, reflecting higher permeability as demonstrated in immunohistochemical studies [20-22]. One hypothesis could be that the acquisition time is not long enough to attempt equalisation of the concentrations between the intra- and extravascular space and thus to provide optimal information concerning extravascular tissue characteristics. A recommended time acquisition for DCE-MRI analysis is classically 10 min [36] so that the concentrations can be equalised between the intra- and extravascular space. Thus, with an acquisition time longer than $320 \mathrm{~s}$, the ability of Ve and PS to discriminate between benign and malignant adnexal tumours should be improved. Third, due to the clinical design of our study, no measurement of gadolinium concentration was performed in the different tissues. However, we performed an optimisation of all acquisition parameters in vivo to be near from linear relationship between [Gd] and signal intensity. Despite of a factor of variability due to possible lack of linearity, our two-compartimental model demonstrated very significant differences regarding quantitative DCE MR parameters between the different groups of tumours. Finally, no difference regarding quantitative 
parameters was found between primary invasive ovarian tumours and metastasis probably due to the small number of metastasis in our population.

In conclusion, this preliminary study shows that quantitative MR analysis of adnexal tumours is feasible and allows accurate differentiation between malignant and benign tumours. Further studies are needed to test the added value of this technique in a larger population and especially to evaluate treatment response. 


\section{REFERENCES}

1 Padhani AR, Dzik-Jurasz A (2004) Perfusion MR imaging of extracranial tumor angiogenesis. Top Magn Reson Imaging 15:41-57

2 O'Connor JP, Jackson A, Parker GJ, Jayson GC (2007) DCE-MRI biomarkers in the clinical evaluation of antiangiogenic and vascular disrupting agents. Br J Cancer 96:189-195

3 Van Vierzen PB, Massuger LF, Ruys SH, Barentsz JO (1998) Borderline ovarian malignancy: ultrasound and fast dynamic MR findings. Eur J Radiol 28:136-142

$4 \quad$ Sohaib SA, Sahdev A, Van Trappen P, Jacobs IJ, Reznek RH (2003) Characterization of adnexal mass lesions on MR imaging. AJR Am J Roentgenol 180:1297-1304

5 Thomassin-Naggara I, Toussaint I, Perrot N, et al. (2011) Characterization of Complex Adnexal Masses: Value of Adding Perfusion- and Diffusion-weighted MR Imaging to Conventional MR Imaging. Radiology 258:793-803

6 Thomassin-Naggara I, Darai E, Cuenod CA, Rouzier R, Callard P, Bazot M (2008) Dynamic Contrast-Enhanced Magnetic Resonance Imaging: a Useful Tool for Characterizing Ovarian Epithelial Tumors. J Magn Reson Imaging 28:111-120

7 Brix G, Semmler W, Port R, Schad LR, Layer G, Lorenz WJ (1991) Pharmacokinetic parameters in CNS Gd-DTPA enhanced MR imaging. J Comput Assist Tomogr 15:621-628

8 Tofts PS, Kermode AG (1991) Measurement of the blood-brain barrier permeability and leakage space using dynamic MR imaging. 1. Fundamental concepts. Magn Reson Med 17:357-367

$9 \quad$ Larsson HB, Stubgaard M, Sondergaard L, Henriksen O (1994) In vivo quantification of the unidirectional influx constant for Gd-DTPA diffusion across the myocardial capillaries with MR imaging. J Magn Reson Imaging 4:433-440

10 Timmerman D, Valentin L, Bourne TH, Collins WP, Verrelst H, Vergote I (2000) Terms, definitions and measurements to describe the sonographic features of adnexal tumors: a consensus opinion from the International Ovarian Tumor Analysis (IOTA) Group. Ultrasound Obstet Gynecol 16:500-505

11 Thomassin-Naggara I, Balvay D, Cuenod CA, Darai E, Marsault C, Bazot M (2010) Dynamic contrast-enhanced MR imaging to assess physiologic variations of myometrial perfusion. Eur Radiol 20:984-994

12 Cenic A, Nabavi DG, Craen RA, Gelb AW, Lee TY (2000) A CT method to measure hemodynamics in brain tumors: validation and application of cerebral blood flow maps. AJNR Am J Neuroradiol 21:462-470

13 Cenic A, Nabavi DG, Craen RA, Gelb AW, Lee TY (1999) Dynamic CT measurement of cerebral blood flow: a validation study. AJNR Am J Neuroradiol 20:63-73

14 Brix G, Bahner ML, Hoffmann U, Horvath A, Schreiber W (1999) Regional blood flow, capillary permeability, and compartmental volumes: measurement with dynamic CT - initial experience. Radiology 210:269-276

15 Pradel C, Siauve N, Bruneteau G, et al. (2003) Reduced capillary perfusion and permeability in human tumour xenografts treated with the VEGF signalling inhibitor ZD4190: an in vivo assessment using dynamic MR imaging and macromolecular contrast media. Magn Reson Imaging 21:845-851

16 De Bazelaire C, Siauve N, Fournier L, et al. (2005) Comprehensive model for simultaneous MRI determination of perfusion and permeability using a blood-pool agent in rats rhabdomyosarcoma. Eur Radiol 15:2497-2505 
17 Balvay D, Tropres I, Billet R, et al. (2009) Mapping the zonal organization of tumor perfusion and permeability in a rat glioma model by using dynamic contrastenhanced synchrotron radiation CT. Radiology 250:692-702

18 Balvay D, Frouin F, Calmon G, et al. (2005) New criteria for assessing fit quality in dynamic contrast-enhanced T1-weighted MRI for perfusion and permeability imaging. Magn Reson Med 54:868-877

19 Fleischer AC, Rodgers WH, Kepple DM, Williams LL, Jones HWd (1993) Color Doppler sonography of ovarian masses: a multiparameter analysis. J Ultrasound Med 12:41-48

20 Abu-Jawdeh GM, Faix JD, Niloff J, et al. (1996) Strong expression of vascular permeability factor (vascular endothelial growth factor) and its receptors in ovarian borderline and malignant neoplasms. Lab Invest 74:1105-1115

21 Yamamoto S, Konishi I, Mandai M, et al. (1997) Expression of vascular endothelial growth factor (VEGF) in epithelial ovarian neoplasms: correlation with clinicopathology and patient survival, and analysis of serum VEGF levels. Br J Cancer 76:1221-1227

22 Chen H, Ye D, Xie X, Chen B, Lu W (2004) VEGF, VEGFRs expressions and activated STATs in ovarian epithelial carcinoma. Gynecol Oncol 94:630-635

23 Thomassin-Naggara I, Bazot M, Darai E, Callard P, Thomassin J, Cuenod CA (2008) Epithelial ovarian tumors: value of dynamic contrast-enhanced MR imaging and correlation with tumor angiogenesis. Radiology 248:148-159

24 Bazot M, Nassar-Slaba J, Thomassin-Naggara I, Cortez A, Uzan S, Darai E (2006) MR imaging compared with intraoperative frozen-section examination for the diagnosis of adnexal tumors; correlation with final histology. Eur Radiol 16:26872699

25 Thomassin-Naggara I, Darai E, Cuenod CA, et al. (2009) Contribution of diffusionweighted MR imaging for predicting benignity of complex adnexal masses. Eur Radiol 19:1544-1552

26 Bakir B, Bakan S, Tunaci M, et al. (2010) Diffusion-weighted imaging of solid or predominantly solid gynaecological adnexial masses: is it useful in the differential diagnosis? Br J Radiol 84(1003):600-611.

27 Takeuchi M, Matsuzaki K, Nishitani H (2010) Diffusion-weighted magnetic resonance imaging of ovarian tumors: differentiation of benign and malignant solid components of ovarian masses. J Comput Assist Tomogr 34:173-176

28 Fujii S, Matsusue E, Kanasaki Y, et al. (2008) Detection of peritoneal dissemination in gynecological malignancy: evaluation by diffusion-weighted MR imaging. Eur Radiol 18:18-23

29 Satoh Y, Ichikawa T, Motosugi U, et al. (2011) Diagnosis of peritoneal dissemination: comparison of 18F-FDG PET/CT, diffusion-weighted MRI, and contrast-enhanced MDCT. AJR Am J Roentgenol 196:447-453

30 Vergote I, Trope CG, Amant F, et al. (2010) Neoadjuvant chemotherapy or primary surgery in stage IIIC or IV ovarian cancer. N Engl J Med 363:943-953

31 Barentsz JO, Berger-Hartog O, Witjes JA, et al. (1998) Evaluation of chemotherapy in advanced urinary bladder cancer with fast dynamic contrast-enhanced MR imaging. Radiology 207:791-797

32 Padhani AR (2002) Dynamic contrast-enhanced MRI in clinical oncology: current status and future directions. J Magn Reson Imaging 16:407-422

33 Padhani AR, Hayes C, Assersohn L, et al. (2006) Prediction of clinicopathologic response of breast cancer to primary chemotherapy at contrast-enhanced MR imaging: initial clinical results. Radiology 239:361-374 
34 Padhani AR, Hayes C, Landau S, Leach MO (2002) Reproducibility of quantitative dynamic MRI of normal human tissues. NMR Biomed 15:143-153

35 Mitchell CL, O'Connor JP, Jackson A, et al. (2010) Identification of early predictive imaging biomarkers and their relationship to serological angiogenic markers in patients with ovarian cancer with residual disease following cytotoxic therapy. Ann Oncol 21:1982-1989

36 Padhani AR, Husband JE (2001) Dynamic contrast-enhanced MRI studies in oncology with an emphasis on quantification, validation and human studies. Clin Radiol 56:607-620 


\section{FIGURES}

Figure 1: Regions of interest (ROI)

A: Axial T2-weighted image $(\mathrm{TR}=6790, \mathrm{TE}=89)$

B: Axial DCE T1-weighted image ( $\mathrm{TR}=27, \mathrm{TE}=2.24)$

On axial or axial oblique plane DCE T1-weighted images, ROIs were drawn over the external iliac artery (continuous black line $=$ ROI) and the solid tissue of the adnexal mass (dotted white line = ROI). In this example, the adnexal mass was a left ovarian fibroma which corresponded to a purely benign solid adnexal tumour

Figure 2: Typical adnexal enhancement curves of malignant and benign adnexal tumours

Figure 3: Comparison of the accuracy of different AUC of dynamic parameters

Figure 4: Comparison of tissue blood flow $\left(\mathrm{F}_{\mathrm{T}}\right)$ and lag time $(\mathrm{Dt})$ between different

subtypes of malignant ovarian tumours

Lines are medians and interquartile ranges. Each point corresponds to an ovarian tumour 


\section{APPENDIX}

In the two-compartment model shown in Figure 2, measurements are translated into quantities of contrast agent in voxels of tissue as follows:

$$
\begin{aligned}
& \mu_{a r t} / k=\frac{Q_{\text {art }}}{V_{\text {art }}}+n_{\text {art }}=C_{b, a r t}+n_{\text {art }}=q_{\text {art }}+n_{\text {art }} \\
& \mu_{T} / k=\frac{Q_{T}}{V_{T}}+n_{T}=\frac{Q_{c}+Q_{e}}{V_{T}}+n_{T}=q_{c}+q_{e}+n_{T}=q_{T}+n_{T}
\end{aligned}
$$

where $\mu$ are the measures of the contrast enhancement $S(t)-S(0)$ in arterial and tissue regions, with $S$ the MRI intensity at a given time $t$, and the indices indicating the arterial (art), tissue (T), capillary (c) and interstitial (e) zones; $\mathrm{V}$ are the volumes of the regions and $\mathrm{Q}$ the contrast agent quantities in these regions, and $\mathrm{q}$ are the equivalent quantities per volume of the corresponding total measured region. Noise is represented by $\mathrm{n}$ and the linear coefficient between contrast enhancement and concentration by k. $\mathrm{C}_{\mathrm{b} \text {,art }}$ is the contrast agent concentration in the artery.

Intermediate plasma variables are defined in the blood compartment for a more readable pharmacokinetic model: the tissue plasma volume $\mathrm{Vp}=(1-\mathrm{Hc}) \cdot \mathrm{Vb}$ and the tissue plasma perfusion $\mathrm{Fp}=(1-\mathrm{Hc}) \cdot \mathrm{Fb}$, where $\mathrm{Hc}$ is the hematocrit in small vessels. Then, the incoming plasma concentration can be determined, at each time $\mathrm{t}$, by:

$$
C_{p, a r t}(t)=q_{\text {art }}(t-D t) /(1-H a)
$$

where $\mathrm{Dt}$ is the artery to tissue delay, corresponding to the time necessary for the blood to go from the large artery (AIF measure) to the arterioles of the tissue of interest, and Ha the hematocrit in large arteries. The outgoing plasma concentration is:

$$
C_{p, v e i n}(t)=q_{c}(t) / v_{p}
$$

where $t$ min is the minimal arteriole to venule delay and $V p$ is the plasma volume fraction defined by $\mathrm{vp}=\mathrm{Vp} / \mathrm{V}_{\mathrm{T}}$. The pharmacokinetic two-compartmental model can then be written as follows:

$$
\left\{\begin{array}{l}
\frac{d q_{c}}{d t}=F_{p} \cdot\left(C_{p, a r t}(t)-C_{p, v e i n}(t)\right)-\frac{P S}{v_{p}} \cdot q_{c}+\frac{P S}{v_{e}} \cdot q_{e} \\
\frac{d q_{e}}{d t}=\frac{P S}{v_{p}} \cdot q_{c}-\frac{P S}{v_{e}} \cdot q_{e}
\end{array}\right.
$$

where $\mathrm{dq} / \mathrm{dt}$ is the time derivation of the quantity q of the agent in the capillary (c) and interstitial (e) compartments and PS is the permeability-surface product and where the interstitial volume fraction ve is defined by ve $=\mathrm{Ve} / \mathrm{V}_{\mathrm{T}}$. When $\mathrm{C}$ and $\mathrm{q}$ are replaced by $\mu$, the factor $\mathrm{k}$, found in each term of the equation, is nullified. 
TABLES

Table 1: Morphological MR characteristics of adnexal tumours

\begin{tabular}{|l|c|c|c|}
\hline MR findings & $\begin{array}{c}\text { Benign } \\
(\mathbf{n}=\mathbf{1 8})\end{array}$ & $\begin{array}{c}\text { Malignant } \\
(n=38)\end{array}$ & $\boldsymbol{P}$ \\
\hline Size of tumour (mm) & $70.5(45-110)^{*}$ & $74(49-117)^{*}$ & 0.74 \\
\hline Purely solid & $50 \%(9)$ & $26.3 \%(10)$ & 0.12 \\
Mixed & $50 \%(9)$ & $73.7 \%(28)$ & \\
\hline Thickened septa & $11.1 \%(2)$ & $28.9 \%(11)$ & 0.18 \\
\hline Vegetation & $11.1 \%(2)$ & $36.8 \%(14)$ & 0.06 \\
\hline Solid portion & $27.7 \%(5)$ & $57.8 \%(22)$ & 0.05 \\
\hline Size of solid tissue $(\mathrm{mm})$ & $34.5(12-70)^{*}$ & $48.5(26-60)^{*}$ & 0.52 \\
\hline
\end{tabular}

* Median value (interquartile range)

Table 2: Quantitative DCE-MRI characteristics of adnexal tumours

\begin{tabular}{|l|l|l|l|}
\hline & $\begin{array}{l}\text { Benign } \\
(n=18)\end{array}$ & $\begin{array}{l}\text { Malignant } \\
(n=38)\end{array}$ & $P$ \\
\hline $\mathrm{F}_{\mathrm{T}}\left(\mathrm{mL} \cdot \mathrm{min}^{-1} .100 \mathrm{~mL}^{-1}\right)$ & $16.1(6.2-37.2)$ & $95.2(39.3-128.7)$ & $<0.0001$ \\
\hline Vb (\%) & $12.1(7.7-15.7)$ & $24.0(15.1-36.1)$ & 0.0006 \\
\hline PS (mL.min $\left.{ }^{-1} .100 \mathrm{~mL}^{-1}\right)$ & $2.7(1.4-7.0)$ & $4.2(3-6.8)$ & 0.09 \\
\hline Ve (\%) & $18.1(10.2-30.8)$ & $11.7(7.0-18.4)$ & 0.04 \\
\hline Dt (s) & $3.4(1.4-7.9)$ & $5.4(3.3-7.1)$ & 0.18 \\
\hline rAUC & $0.15(0.08-0.22)$ & $0.34(0.20-0.47)$ & 0.0002 \\
\hline
\end{tabular}

Values are median values (interquartile range).

$P$ values were calculated with the Mann-Whitney test

$\mathrm{F}_{\mathrm{T}}=$ tissue blood flow, $\mathrm{Vb}=$ blood volume fraction; $\mathrm{PS}=$ =ermeability-surface area product;

$\mathrm{Ve}=$ extracapillary and extracellular (interstitial) volume fraction; $\mathrm{Dt}=\mathrm{lag}$ time 
Table 3: Accuracy of different dynamic MR parameters to differentiate benign from malignant tumours

\begin{tabular}{lcccc}
\hline & $\begin{array}{c}\text { Cut-off } \\
\text { value }\end{array}$ & $\begin{array}{c}\text { Sensitivity } \\
(\%)\end{array}$ & $\begin{array}{c}\text { Specificity } \\
(\%)\end{array}$ & AUROC \\
\hline $\mathrm{F}_{\mathrm{T}}\left(\mathrm{mL} \cdot \mathrm{min}^{-1} .100 \mathrm{~mL}^{-1}\right)$ & $>39.5$ & 73.7 & 88.9 & $0.862(0.750-0.943)$ \\
$\mathrm{Vb}(\%)$ & $>13.4$ & 86.8 & 72.2 & $0.787(0.657-0.885)$ \\
$\mathrm{PS}\left(\mathrm{mL} \cdot \mathrm{min}^{-1} .100 \mathrm{~mL}^{-1}\right)$ & $>2.5$ & 84.2 & 50 & $0.640(0.501-0.764)$ \\
$\mathrm{Ve}(\%)$ & $>20.3$ & 84.2 & 50 & $0.664(0.525-0.784)$ \\
$\mathrm{Dt}(\mathrm{s})$ & $>3.13$ & 81.5 & 50 & $0.610(0.470-0.737)$ \\
\hline rAUC & $>0.28$ & 71.0 & 83.3 & $0.810(0.683-0.902)$ \\
\hline
\end{tabular}

